\title{
Sleep attacks in patients taking dopamine agonists: review
}

\author{
Carl Nikolaus Homann, Karoline Wenzel, Klaudia Suppan, Gerd Ivanic, Norbert Kriechbaum,
} Richard Crevenna, Erwin Ott

\begin{abstract}
Objectives To assess the evidence for the existence and prevalence of sleep attacks in patients taking dopamine agonists for Parkinson's disease, the type of drugs implicated, and strategies for prevention and treatment.

Design Review of publications between July 1999 and May 2001 in which sleep attacks or narcoleptic-like attacks were discussed in patients with Parkinson's disease.

Results 124 patients with sleep events were found in 20 publications. Overall, $6.6 \%$ of patients taking dopamine agonists who attended movement disorder centres had sleep events. Men were over-represented. Sleep events occurred at both high and low doses of the drugs, with different durations of treatment (0-20 years), and with or without preceding signs of tiredness. Sleep attacks are a class effect, having been found in patients taking the following dopamine agonists: levodopa (monotherapy in 8 patients), ergot agonists (apomorphine in 2 patients, bromocriptine in 13, cabergoline in 1 , lisuride or piribedil in 23 , pergolide in 5 ,) and non-ergot agonists (pramipexole in 32, ropinirole in 38). Reports suggest two distinct types of events: those of sudden onset without warning and those of slow onset with prodrome drowsiness. Conclusion Insufficient data are available to provide effective guidelines for prevention and treatment of sleep events in patients taking dopamine agonists for Parkinson's disease. Prospective population based studies are needed to provide this information.
\end{abstract}

\section{Introduction}

Increased daytime somnolence has long been recognised as a side effect of dopaminergic drugs, although there were no descriptions on sudden irresistible sleep attacks in clinical trials or national pharmacovigilance databases before the study by Frucht and others. ${ }^{1-3}$ Pramipexole and ropinirole were the first dopamine agonists associated with road crashes, but now all dopamine drugs are implicated. ${ }^{3}{ }^{4}$ The legitimacy of sleep attacks as a phenomenon distinct from normal somnolence has been questioned, and the associated medicolegal and social issues have generated much controversy. ${ }^{4-10}$

We aimed to determine whether sleep attacks do exist or whether they are indistinguishable from drug induced somnolence and excessive sleepiness, the prevalence of sleep attacks, which dopamine drugs are implicated, whether attacks are predictable and preventable, and whether they are treatable.

\section{Methods}

We searched for the key words "Parkinson" or "Parkinson's disease" or "parkinsonism," and "sleep" or "narcoleptic" or "attacks" and a combination of these between July 1999 and May 2001. We did not search prior to these dates because there were no reported cases of sleep attacks until 1999. ${ }^{3}$ We identified relevant publications from electronic searches of three general biomedical databases (Medline, Embase, Pascal) and from hand searches of major neurological journals (Brain, Annals of Neurology, Archives of Neurology, Neurology, Movement Disorders, Journal of Neurology Neurosurgery and Psychiatry, Journal of Neurology, Nervenarzt) and general medical journals (Lancet, New England Journal of Medicine, British Medical Journal), the abstracts of congresses (13th international congress on Parkinson's disease, international symposium on gait disorders, second international congress on mental dysfunction in Parkinson's disease, American Academy of Neurology 52nd meeting, 10th meeting of the European Neurological Society, sixth international congress of Parkinson's disease and movement disorders), and the reference lists of relevant articles.

Sleep attacks are defined as events of overwhelming sleepiness that occur without warning or with a prodrome sufficiently short or overpowering to prevent protective measures. ${ }^{10}$ Most of the reports we surveyed were issued before this definition was published, so the inclusion criteria for sleep attacks in these studies varied greatly. To overcome this methodological problem, we used the reported characteristics of the onset of the event and the reliability of witnesses to the event to grade these phenomena into sleep attacks (definite, probable, and possible), sleep episodes, and sleep events not otherwise specified (box).

\section{Results}

We identified 20 publications covering sleep events in 124 patients (table 1). We classified sleep events into 96 sleep attacks ( 5 definite, 8 probable, and 83 possible), 4 sleep episodes, and 23 sleep events not otherwise classified. Overall, 38 patients were taking ropinirole, 32 pramipexole, 13 bromocriptine, 23 either lisuride or piribedil, 5 pergolide, 2 apomorphine, and 1 cabergoline. Eight patients were receiving levodopa monotherapy, and in two the dopamine agonist was not specified. Complete information on sex, age, and duration of exposure to the drug before the onset of a sleep attack was available in 33 patients (table 2). The age ranged from 34-87 years, and two thirds of the patients were male. Parkinson's disease was staged from Hoehn and Yahr 1 to 3, and the duration of disease ranged from 1-20 years. Two patients had sleep events on first exposure to the drug, but in the others they occurred with recurrent exposures (2 weeks to 20 years). ${ }^{11}$

\section{Nature of sleep events}

Circumstances around and before sleep attacks

The circumstances at the time of the sleep event were described in 29 patients, with several reporting more than one event. In 17 cases the sleep event happened during driving, leading to road crashes in 10. In 12 cases non-driving attacks occurred during standing (3

\author{
Department of \\ Neurology, Karl \\ Franzens University \\ Hospital, A-8036 \\ Graz, Austria \\ Carl Nikolaus \\ Homann \\ consultant \\ Karoline Wenzel \\ registrar \\ Klaudia Suppan \\ registrar \\ Gerd Ivanic \\ consultant \\ Richard Crevenna \\ registrar \\ Erwin Ott \\ head \\ Department of \\ Psychiatry, Karl \\ Franzens University \\ Hospital \\ Norbert \\ Kriechbaum \\ associate professor \\ Correspondence to: \\ C N Homann \\ nik.homann@ \\ kfunigraz.ac.at
}

BMJ 2002;324:1483-7 


\section{Classification of sleep events}

Sudden irresistible sleep attack

Explicitly stated that event was sudden and irresistible, or description of event is as such that suddenness and irresistibility can be concluded-for example, patient fell into her dish while eating

Definite sleep attack

Suddenness and irresistibility of event is explicitly confirmed by reliable sources-for example, trained medical staff or objective relative not under psychological stress

Probable sleep attack

Suddenness and irresistibility of event is explicitly confirmed by sources with questionable reliability-for example, relative under psychological stress who was involved in car crash due to sleep attack

\section{Possible sleep attack}

Suddenness and irresistibility of event not confirmed by sources other than patient or account of confirming source not given

\section{Sleep episode}

Not sudden but irresistible onset of daytime sleep, particularly waves of sleepiness with sufficient prodrome to counteract mishaps

\section{Sleep event not otherwise specified}

"Sleep attack" or "sleep event" used in publication without explicit details on irresistibility or suddenness and without information on source reliability

patients), walking (1), talking (3), eating (3), writing (1), and grooming a pet (1). Twenty patients had recurrent sleep events.

In 11 cases episodes of somnolence and in 10 cases non-driving attacks preceded an attack while driving.
In three cases both somnolence and non-driving attacks were present in the patient before an attack while driving.

Montastruc and others found a strong association between dysautonomia and sleep events in 159 patients with Parkinson's disease. ${ }^{23}$ In two patients in whom genetic studies were performed, no HLA-DR2 serotype (narcolepsy associated haplotype) was found. ${ }^{21}$

Clinical and electrophysiological descriptions of time course We identified six reports on 16 separate sleep events describing their exact time course: three with complete information and three with rudimentary information. Electroencephalography was performed in six patients, ${ }^{5}{ }^{14}{ }^{21}$ but only three sleep events were captured in two of the patients. ${ }^{51}$

We identified two distinct clinical courses from the available data: a sudden irresistible attack of sleep and sleep episodes.

Patients with sudden irresistible attacks of sleep suddenly fell asleep without warning signs. ${ }^{11}$ A patient described this as "not like falling asleep but more like a short circuit."10 After two to five minutes, during which time the patients were not susceptible to painful stimuli, they abruptly recovered to full wakefulness, felt well but could not give any account of the preceding event. ${ }^{11321}$ Electroencephalograms showed a sleep latency of less than one minute. ${ }^{21} \mathrm{~A}$ mean sleep latency of 16.9 minutes suggested a normal background of wakefulness.

Patients with sleep episodes reported prodromal signs of tiredness-sometimes experienced as waves of sleepiness-followed by a slow and irresistible drowsing off, with sleep lasting about an hour. They could be awakened during this sleep but could not maintain

Table 1 Key characteristics and methodological quality of included studies

\begin{tabular}{|c|c|c|c|c|c|c|c|}
\hline Reference & Format & Content & Demographic data* & Description of event & Drug & $\begin{array}{c}\text { No of } \\
\text { patients }\end{array}$ & Country \\
\hline Frucht et al $1999^{3}$ & Short report & Retrospective study & Complete & Vague & Pramipexole, ropinirole & 8 & United States \\
\hline Arnold $2000^{12}$ & Letter & Case report & Complete & Vague & Pergolide & 1 & Germany \\
\hline Hoehn $2000^{13}$ & Letter & Case report & $\begin{array}{c}\text { Some or summary } \\
\text { data }\end{array}$ & Vague & Pramipexole & 9 & United States \\
\hline Frucht $2000^{9}$ & Letter & Comment & None or inadequate & None & Pramipexole, ropinirole & 24 & United States \\
\hline Frucht et al $2000^{10}$ & Review & Editorial & None or inadequate & Vague & Not stated & 1 & United States \\
\hline Hoegl et al $2000^{14}$ & Abstract & Prospective study & Complete & Detailed & Levodopa & 1 & Austria \\
\hline Homann et al $2000^{11}$ & Abstract & Case report & Complete & Detailed & Apomorphine & 2 & Austria \\
\hline Homann et al 2000 & Not published & Case report & Complete & Detailed & Pergolide & 1 & Austria \\
\hline Ferreira et al $2000^{15}$ & Letter & Case report & Complete & Vague & $\begin{array}{l}\text { Pergolide, bromocriptine, } \\
\text { piribedil }\end{array}$ & 3 & Portugal, France \\
\hline Paladini et al $2000^{16}$ & Abstract & Case report & $\begin{array}{c}\text { Some or summary } \\
\text { data }\end{array}$ & Vague & Ropinirole & 2 & Italy \\
\hline Schapira $2000^{17}$ & Letter & Case report & $\begin{array}{c}\text { Some or summary } \\
\text { data }\end{array}$ & Vague & Pergolide & 2 & United States \\
\hline Ferreira et al $2000^{18}$ & Abstract & Case report & $\begin{array}{c}\text { Some or summary } \\
\text { data }\end{array}$ & Vague & Levodopa & 4 & Portugal, France \\
\hline Ferreira et al $2000^{19}$ & Abstract & Prospective study & $\begin{array}{c}\text { Some or summary } \\
\text { data }\end{array}$ & Vague & $\begin{array}{l}\text { Levodopa, bromocriptine, } \\
\text { lisuride }\end{array}$ & 6 & Portugal, France \\
\hline Hauser et al $2000^{20}$ & Abstract & Case report & Complete & Vague & Pramipexole & 1 & United States \\
\hline Ebersbach et al $2000^{21}$ & Abstract & Case report & $\begin{array}{c}\text { Some or summary } \\
\text { data }\end{array}$ & Detailed & Levodopa, cabergoline & 1 & Germany \\
\hline Hauser et al $2000^{20}$ & Article & Case report & Complete & Vague & Pramipexole & 8 & United States \\
\hline Olanow et al $2000^{4}$ & Article & Viewpoint & - & - & - & - & United States \\
\hline Schafer and Greulich $2000^{22}$ & Case report & Case report & Complete & Vague & Ropinirole & 1 & Germany \\
\hline Montastruc et al $2000^{23}$ & Abstract & Prospective study & None or inadequate & None & $\begin{array}{l}\text { Pramipexole, bromocriptine, } \\
\text { piribedil, lisuride }\end{array}$ & 48 & France \\
\hline Pirker and Happe $2000^{24}$ & Letter & Case report & Complete & Vague & Ropinirole & 1 & Austria \\
\hline
\end{tabular}

${ }^{*}$ Complete description includes disease duration and stage as well as therapy and length of therapy until sleep event. 
Table 2 Profile of patients with complete information

\begin{tabular}{|c|c|c|c|c|c|c|c|}
\hline Dopamine agonist & $\begin{array}{c}\text { No of } \\
\text { patients }\end{array}$ & $\begin{array}{l}\text { Male:female } \\
\text { ratio }\end{array}$ & $\begin{array}{c}\text { Age } \\
\text { (years) }\end{array}$ & $\begin{array}{l}\text { Disease } \\
\text { stage }^{*}\end{array}$ & $\begin{array}{l}\text { Disease duration } \\
\text { (years) }\end{array}$ & Exposure & Dose (mg) \\
\hline Levodopa & 4 & $3: 1$ & $62-87$ & $2-3$ & $9-20$ & Up to 20 years & $200-1250$ \\
\hline Apomorphine & 2 & $1: 1$ & $58-64$ & $1-3$ & $2-6$ & First & 2 \\
\hline Pergolide & 4 & $2: 2$ & $57-61$ & 2 & $5-6$ & 1 month to 3 years & $3-5$ \\
\hline Pramipexole & 18 & $14: 4$ & $34-83$ & $1-3$ & $1-3$ & 2 months to 5 years & $0.75-4.5$ \\
\hline Ropinirole & 3 & $1: 2$ & $42-64$ & $2-3$ & 5 & 2 months to 5 years & $8-24$ \\
\hline Bromocriptine & 1 & $1: 0$ & 72 & 3 & 15 & 7 years & 30 \\
\hline Piribedil & 1 & $1: 0$ & 69 & 3 & 2 & - & 150 \\
\hline Total & 33 & $2.3: 1$ & $34-87$ & $1-3$ & $1-20$ & $0-20$ years & \\
\hline
\end{tabular}

*Staged according to Hoehn and Yahr, from 1 (mild unilateral disease) to 5 (complete disability).

wakefulness despite interventions. ${ }^{14}$ On awakening they acknowledged being asleep unwillingly. ${ }^{14}$ Two patients with waves of sleepiness showed a background of sleepiness in the mean sleep latency test. ${ }^{20}$

\section{Epworth sleepiness scale}

None of 79 patients with positive scores on the Epworth sleepiness scale had had sleep events in the past. ${ }^{25}{ }^{26}$ The scale comprises eight questions about falling asleep in inappropriate but tiring situations. Possible ratings for each question are 0 (never), 1 (slight chance), 2 (moderate chance), and 3 (high chance). A score of 14 or higher is considered indicative of excessive daytime sleepiness. ${ }^{26}$ Of the four patients tested who had had sleep events none showed a clear positive Epworth score $(0,8,11,12) .{ }^{11}{ }^{27}$ Lang found the scale to have a sensitivity for prediction of falling asleep while driving of less than $50 \%{ }^{28}$

\section{Prevalence of sleep events}

Two retrospective and seven prospective studies, totalling 1787 patients with Parkinson's disease, gave data on prevalence on sleep events. They occurred in $6.6 \%$ (range $0 \%-30 \%$ ) of patients taking dopamine drugs (table 3). In Montastruc and others' study of 236 patients with Parkinson's disease, more sleep events occurred with ropinirole (41\%) than with bromocriptine $(36 \%)$, lisuride $(27 \%)$, or piribedil $(30 \%){ }^{29}$ But differences between agonists were not significant according to Hobson and others. ${ }^{30}$

\section{Treatment of sleep events}

Treatment strategies were reported in 30 of the 123 patients (table 4). Active treatment was effective with modafinil in one patient with waves of sleepiness and with amantadine in one patient with possible sleep attacks. In 25 patients the drug dose was either reduced (10 patients) or discontinued (15 patients), which prompted either complete (22 patients) or partial (3) cessation of sleep events. Switching from one dopamine agonist to another was reported in three cases and brought about initial remission in two patients but recurrence in one. One of the two patients for whom remission of sleep attacks was initially reported represented after several months (W Pirker, personal communication, 2001). An adjustment of the intake schedule to the patients' need to be awake at certain times was successfully attempted in two patients taking levodopa. ${ }^{15}$ To avoid car crashes, one patient with episodic waves of sleepiness would pull over and take a nap if tiredness occurred while driving. ${ }^{15}$

\section{Discussion}

Up to $30 \%$ of patients taking dopamine agonists for Parkinson's disease have sleep attacks. These are a class phenomenon, and their prediction, prevention, and treatment are yet to be solved.

The concept of sleep attacks has been disputed by several authors, who speculate that these episodes are but exaggerated daytime drowsiness. ${ }^{3-8}$ But recent detailed first hand reports by medical specialists are of particular value as they support the existence of two types of sleep events. ${ }^{10111420}$

A limitation of our review is that publication bias might have led to an overestimation of the prevalence of sleep attacks. Also data were derived from clinics dealing with movement disorders, which might not be representative.

Dealing with sleep attacks and their consequences

Driving presents problems in patients with sleep events because of their decreased awareness of drowsiness over time and because passengers may not notice their reduced vigilance while driving. ${ }^{4}$ However, some potentially disastrous outcomes can be prevented. ${ }^{4}$ By definition the patients in our review experienced sleep episodes. Prevention of car crashes relies on the detection of patients at risk and advising them not to drive.

Table 3 Prevalence of sleep events in reported studies

\begin{tabular}{|c|c|c|c|c|c|}
\hline Reference & Study design & Patient selection & Patient recruitment & No of patients & $\begin{array}{l}\text { Prevalence of } \\
\text { sleep events (\%) }\end{array}$ \\
\hline Hauser et al $2000^{20}$ & Retrospective & Parkinson's disease & Centre for movement disorders & 37 & 24 \\
\hline Frucht et al $2000^{10}$ & Retrospective & Parkinson's disease & 3 centres for movement disorders & 400 & 2 \\
\hline Montastruc et al $2000^{23}$ & Prospective & Parkinson's disease & Centre for movement disorders & 159 & 30.2 \\
\hline Parkinson Study Group $2000^{33}$ & Prospective & Parkinson's disease & $\begin{array}{c}22 \text { centres for movement } \\
\text { disorders }\end{array}$ & 301 & 1.7 \\
\hline Pal et al $2000^{26}$ & Prospective & Parkinson's disease & Centre for movement disorders & 55 & 0 \\
\hline Montastruc $2001^{29}$ & Prospective & Parkinson's disease & Centre for movement disorders & 236 & 30.5 \\
\hline Hobson et al $2002^{30}$ & Prospective & Parkinson's disease & $\begin{array}{c}18 \text { centres for movement } \\
\text { disorders }\end{array}$ & 638 & 3.8 \\
\hline Ferreira et al $2000^{27}$ & Prospective & Parkinson's disease & Centre for movement disorders & 52 & 12 \\
\hline
\end{tabular}


Table 4 Effect on sleep events of changes in treatment strategy

\begin{tabular}{|c|c|c|c|c|c|}
\hline Strategy & $\begin{array}{l}\text { No of sleep } \\
\text { events }\end{array}$ & Dopamine agonist & Starting dose (mg) & End dose (mg) & Outcome \\
\hline \multirow[t]{2}{*}{ Dose reduction } & 7 & Pramipexole & $4-4.5$ & $?$ & 4 remissions and 3 partial remissions \\
\hline & 3 & Pergolide & $4.5-5$ & 3 & Remission \\
\hline \multirow[t]{2}{*}{ Discontinuation } & 12 & Pramipexole & $1-4.5$ & 0 & Remission \\
\hline & 3 & Ropinirole & $8-24$ & 0 & Remission \\
\hline \multirow[t]{2}{*}{ Switching } & 1 & Pramipexole to ropinirole & 1 & 16 & Recurrence \\
\hline & 1 & Pramipexol to pergolide & 4.5 & 3 & Remission \\
\hline \multirow[t]{2}{*}{ Add-on therapy } & 1 & Pramipexole plus modafinil & 4.5 & $\geqslant 100$ & Remission \\
\hline & 1 & Pramipexole plus amantadine & 4.5 & $?$ & Remission \\
\hline Total & 27 & & & & $\begin{array}{c}25 \text { remissions, } 3 \text { partial remissions, } \\
1 \text { recurrence }\end{array}$ \\
\hline
\end{tabular}

Secondary prevention has been proposed by using the Epworth sleepiness scale, multiple sleep latency test, and polysomnography as screening tools. ${ }^{4}$ Polysomnograms of 27 patients showed no strong association between excessive daytime sleepiness and disrupted night sleep. ${ }^{31}$ Analysis of past sleep events suggested that low sensitivity of screening tools might be increased by adding the inappropriate sleep composite score. ${ }^{30}$ This score was devised to examine the likelihood of falling asleep during five potentially stimulating activities. In contrast to most of the items of the Epworth sleepiness scale, sleep episodes while driving, eating, working, conversing, and doing household chores were thought to represent problematic and pathological excessive daytime sleepiness. ${ }^{30}$ The available data are limited and do not allow either to be considered a reliable predictor of future risks of sleep events.

Little is known about general risk factors of sleep events. Contrary to the findings of Montastruc and others more (70:53) patients in our review had sleep event while taking ergot dopamine agonists. ${ }^{23}{ }^{29}$ These findings have to be treated with caution, however, because of publication and selection bias. Preliminary data suggest that the risk of a sleep event is higher in patients with dysautonomia or males. ${ }^{23}{ }^{29}$ Currently neither a narcolepsy-like Parkinson's disease phenotype nor higher doses of dopamine agonists, duration of treatment, Hoehn and Yahr stage, age, or prior episodes of falling asleep can be considered specific risk factors for sleep events. ${ }^{69132930}$ An intake of sedatives was also not predicative. ${ }^{29}$

With no reliable risk factor available, effective treatment is crucial to counteract the consequences of sleep attacks. Various strategies such as dose alterations or active treatment have been attempted but not in a controlled and prospective way. As switching from one dopamine agonist to another can lead to a recurrence of symptoms, ${ }^{3}$ it seems preferable to reduce the dose of drug. However in only 7 of 30 cases in which treatment modalities were provided did a reduction of dopamine agonist dose result in complete remission of sleep events. Remission was incomplete (but presumably tolerable) in three patients, whereas in 15 the drug was stopped by the doctor. Why this was done was never specified. Because long term side effects can be more disabling than disease related symptoms, low dose therapy that just meets the needs of the patient has become the rule. ${ }^{32}$ A reduction of dose would lead to a worsening of motor symptoms, counter to the primary aim of treating Parkinson's disease. But even in those patients for whom a reduction is initially tolerated, disease progression will inevitably lead to an increased dose, possibly with a renewed risk of later sleep events. These strategies therefore can not be considered good and permanent solutions.

\section{Driving safety}

The health authorities of Canada, the European Union, and the United States have asked the manufacturers of pramipexole and ropinirole to advise doctors to warn patients not to drive or engage in comparable risky activities while taking the drugs. ${ }^{40}$ We found 17 cases where the sleep event occurred during driving, leading to road crashes in 10 cases. Despite the potential danger from driving, experts believe that sleep attacks are too infrequent to recommend that patients taking dopamine agonists for Parkinson's disease stop driving. ${ }^{481033}$ Studies suggest that whether or not patients with Parkinson's take dopamine drugs they do not cause more road crashes than age matched controls. ${ }^{44}$ Recommendations for driving, other than informing patients of a potential risk, should be made with caution until more data are available.

We thank B Homann and R Robinson for their critical remarks on the manuscript.

Contributors: $\mathrm{CNH}$ conceived and designed the study, analysed the data, drafted the article, and supervised the preparation of the article. KW searched and evaluated the literature, analysed the data, and critically revised the article. KS hand searched and evaluated the clinical papers, interpreted the data, and drafted and critically revised the article. GI conceived and designed the study, interpreted the data, and drafted and

\section{What is already known on this topic}

Car crashes in patients with Parkinson's disease have been associated with sleep attacks caused by the dopamine agonists pramipexole and ropinirole

Whether sleep attacks exist, their connection with certain agonists, prevention or treatment, and the justification of legal actions are controversial

\section{What this study adds}

Sleep attacks as a phenomenon distinct from normal somnolence really do exist

They are a class effect of all dopamine drugs

Effective prevention and treatment strategies are lacking, although data are insufficient to justify a general driving ban 
critically revised the article. RC conceived and designed the study, searched and evaluated the literature, interpreted the data, and critically revised the article. NK conceived and designed the study, evaluated the literature, interpreted the data, and critically revised the article. EO conceived and designed the study, critically revised the article, and provided general supervision.

Competing interests: None declared.

Gottwald MD, Bainbridge JL, Dowling GA, Aminoff MJ, Alldredge BK New pharmacotherapy for Parkinson's disease. Ann Pharmacother 1997:31:1205-17.

2 Lledo M. Falling asleep at the wheel: motor vehicle mishaps in people taking pramipexole and ropinirole [comment]. Neurology 2000;54:275.

3 Frucht SJ, Rogers JD, Greene PE, Gordon MF, Fahn S. Falling asleep at the wheel: motor vehicle mishaps in people taking pramipexole and ropinirole. Neurology 1999;52:1908-10.

4 Olanow CW, Schapira AV, Roth T. Waking up to sleep episodes in Parkinson's disease. Mov Disord 2000;15:212-5.

5 Hoegl B, Poewe W. "Sudden sleep attacks" with pramipexole and ropinirole. Neuropsychiatrie 2000;14:191-3.

6 Rye DB, Bliwise DL. Falling asleep at the wheel: motor vehicle mishaps in people taking pramipexole and ropinirole [comment]. Neurolog 2000;54:276.

7 Clarenbach P. Parkinson's disease and sleep. J Neurol 2000;247:20-3.

8 Lachenmayer L. Parkinson's disease and the ability to drive. J Neurol 2000;247:28-30.

9 Frucht SJ. Falling asleep at the wheel: motor vehicle mishaps in people taking pramipexole and ropinirole [comment]. Neurology 2000;54:276-7.

10 Frucht SJ, Greene PE, Fahn S. Sleep episodes in Parkinson's disease: wake-up call. Mov Disord 2000;15:601-3.

11 Homann CN, Wenzel K, Suppan K, Ivanic G, Kriechbaum N, Oh E. Sleep attacks with apomorphine. Wien Klin Wochenschr 2002;114:430-1.

12 Arnold G. Falling asleep at the wheel: motor vehicle mishaps in people taking pramipexole and ropinirole [comment]. Neurology 2000;54:276.

13 Hoehn MM. Falling asleep at the wheel: motor vehicle mishaps in people taking pramipexole and ropinirole [comment]. Neurology 2000;52:275.

14 Hoegl B, Seppi K, Brandauer E, Poewe W, Wenning GK. Irresistible onse of sleep during acute levodopa challenge in multisystem atrophy: a polysomnographic case report. Mov Disord 2000;15:227.

15 Ferreira JJ, Galitzky M, Montastruc JL, Rascol O. Sleep attacks and Parkinson's disease treatment. Lancet 2000;355:1333-4

16 Paladini D, Cinti A, Guidoni P, DiMarzio F, Cocci Grifoni S, Angeleri Sleep attacks in two Parkinson's disease patients taking ropinirole. Mor Disord 2000;15:130-1.

17 Schapira AH. Sleep attacks (sleep episodes) with pergolide. Lancet 2000;355:1332-3.

18 Ferreira JJ, Galitzky M, Brefel-Courbon C, Senard JM, Montastruc JL, Castro-Caldas A, et al. Sleep attacks as an adverse drug reaction of levodopa monotherapy. Mov Disord 2000;15:129.
19 Ferreira JJ, Desboeuf K, Galitzky M, Thalamas C, Brefel-Courbon C, Fabre N, et al. Sleep attacks and Parkinson's disease: results of a questionnaire survey in a movement disorders outpatient clinic. Mov Disord 2000;15:187.

20 Hauser RA, Gauger L, McDowell AW, Zesiewicz TA. Pramipexoleinduced somnolence and episodes of daytime sleep. Mov Disord 2000;15:658-63

21 Ebersbach G, Norden J, Tracik F. Sleep attacks in Parkinson's disease: polysomnographic recordings. Mov Disord 2000;15:187-8.

22 Schafer D, Greulich W. Influence of dopaminergic medication on the vigilance in Parkinson's disease: a case report. Somnologie 2000;4:84-92.

23 Montastruc JL, Brefel-Courbon C, Senard JM, Desboeuf K, Rascol O, Lapeyre-Mestre M. Sudden sleep attacks and antiparkinsonian drugs: a pilot prospective pharmacoepidemiological study. Mov Disord 2000; $15: 130$.

24 Pirker W, Happe S. Sleep attacks in Parkinson's disease. Lancet 2000;356:597-8.

25 Johns MW. A new method for measuring daytime sleepiness: the Epworth sleepiness scale. Sleep 1991;14:540-5.

26 Pal S, Bhattacharya C, Agapito C, Mills J, Chaudhuri R. A comparative study of daytime sleepiness within Parkinson's disease patients treated with cabergoline, pramipexole and levodopa. Mov Disord 2000;15:110-1.

27 Ferreira JJ, Marques MA, Galitzky M, Thalamas C, Despeyroux ML, Brefel-Courbon C, et al. Methodological problems to quantify excessive daytime sleepiness or the risk of sleep episodes in Parkinson's disease. Mov Disord 2000;15:187-8.

28 Lang AE, Hobson DE, Martin W, Rives J. Excessive daytime sleepines and sudden onset sleep in Parkinson's disease: a survey from 18 Canadian movement disorders clinics. Neurology 2001;56:S40.001.

29 Montastruc JL, Brefel-Courbon C, Senard JM, Desboeuf K, Rascol O, Lapeyre-Mestre M. Sleep attacks and antiparkinsonian drugs: a pilot prospective pharmacoepidemiological study. Clin Neuropharmacol 2001:24:181-3.

30 Hobson DE, Lang AE, Martin W, Razmy A, Rivest J, Flemin J. Excessive daytime sleepiness and sudden onset sleep in Parkinson's disease: a survey by the Canadian Movement Disorders Group. JAMA 2002:287:455-63.

31 Rye DB, Bliwise DL, Dihenia B, Gurecki P. Daytime sleepiness in Parkinson's disease. J Sleep Res 2000;9:63-9.

32 Poewe W, Ceballos-Baumann AO, Conrad B. Parkinson-Krankheit. In: Conrad B, Ceballos-Baumann AO, eds. Bewegungsstoe rungen in der Neurologie. Stuttgart, NewYork: Thieme, 1996:30-68.

33 Parkinson Study Group. Pramipexole vs levodopa as initial treatment for Parkinson's disease: a randomized controlled trial. JAMA 2000;284: $1931-8$

34 Homann CN, Trummer M, Wenzel K, Suppan K, Ott E. Sleep attacks and severe road accidents in patients with Parkinson's disease-an infrequent finding. Mov Disord 2001;16:44.

(Accepted 17 May 2002)

\section{My 15 minutes of fame}

Towards the end of last year I wrote a letter to the Times newspaper. It was prompted by what had been a particularly gruelling night shift in casualty, where I had seen few cases that were either an accident or an emergency. I decided to unleash all of my accumulated anger, frustration, and fatigue in the form of a reply to a letter from a general practitioner suggesting that we should charge for the use of medical services. I furiously typed my response by email, and went to sleep at $10 \mathrm{am}$ feeling much relieved.

At $5 \mathrm{pm}$ I awoke to find, to my great surprise, a message on my answering machine from the letters editor of the Times politely asking me to telephone him as he wanted my permission to edit my letter slightly before publication. I duly gave it, and two days later my letter appeared.

Later that morning my telephone rang. It was the Times again; they had received several telephone calls from various institutions interested in my letter, and would I mind if they gave out my telephone number? Cautiously, I agreed. My first proposal was from a national newspaper-could I contribute to an article they were publishing? I stalled, realising I was slightly out of my depth, and called the BMA Press Office, whose advice was extremely helpful. I decided to decline the newspaper's offer, as most of the content of the article had already been determined and I would have no control over the context in which the paper published any information I gave.

Next came a call from a national radio station asking if I would come to their studios to participate in a live radio debate. By now I was becoming twitchy-what had I unleashed? After all, I was just a junior senior house officer in Accident and Emergency, not a spokesman for the NHS. I decided I had best talk to one of my consultants. Luckily she was superb, telling me what a great letter it was and suggesting I speak to the hospital's public relations officer. She in turn was also was extremely encouraging and helped me to fend off the national newspaper, which pestered me with phone calls trying to get me to reverse my decision not to contribute to the article.

I had also allowed my email address to be published with the letter, and, on checking my inbox, I found that I had received several replies with views ranging from the frankly communist to the starkly fascist.

By the end of the day, I had not slept and was just as angry and frustrated as I had been originally, but this time with the persistent attention I had received from the media. But, as I went back to work that night, I noticed that something had changed. After the events of the day it was actually a welcome relief to sit and talk to my first patient, who I would have seen as a complete heartsink earlier in the week. As the night went on, I began to appreciate the rich tapestry of life that streamed before me; the people who wanted my attention now were genuine and sincere, a far cry from those who had chased me earlier that day. My enthusiasm renewed, that night I saw each patient with more natural gusto than I had ever known before.

Alistair Lindsay accident and emergency senior house officer, St Mary's Hospital, London 